they are unacquainted with the work of games theorists and welfare economists. Hare, however, shows himself well aware of the difficulties; and there is great force in his contention that they face all moralists who attach any importance to doing social good or preventing social harm, and not just utilitarians.

Part III seeks to show why we should go in for critical thinking, conceding that there is no logically compelling argument against the amoralist, but endorsing a probable argument in prudence against bringing up children to be such. It is further argued that it is logically impossible for there to be a consistent, non-utilitarian fanatic. Here, as throughout, it is maintained that critical moral reasoning is both philosophically justified in terms of the concept of moral judgments as universalizable prescriptions and capable of directing ideally acute, sensitive, fully-informed people to rational solutions to practical questions. Actual human beings, of course, fall short; but rational solutions remain possible in principle.

Hare is unquestionably the most influential British moral philosopher of the last 30 years. His book will inevitably be of immense interest to fellow philosophical practitioners, who will want to see how he has qualified and developed his views. Hare, however, clearly hopes to reach a wider public, feeling that 'unless some way is found of talking about [urgent practical issues] rationally and with hope of agreement, violence will finally engulf the world'. I am sure that an understanding of the present book would greatly improve public discussion; but I fear that it may not exert the wide direct influence that it should. Hare is an exceptionally careful thinker and a clear-headed writer; but his book is not wholly accessible to the lay reader. It comes across as a report on work in progress, shaped as often as not by the objections of critics, and compressed by a notable reluctance to bore the reader by repetition of other writings or extended discussion of matters not central to the main argument. These intuitions have merit; but critical thought should convince the author that he could do good by expressing himself at greater length and in a more relaxed and less argumentative manner. $\mathrm{He}$ acknowledges debts to Kant and Mill. I think he could surpass the rigour of the former in a work as widely readable as the Utilitarianism or Liberty of the latter.

PROFESSOR R F ATKINSON Department of Philosophy The University of Exeter

\section{Justice and Health Care}

Ed Earl E Shelp

Holland, D Reidel Publishing Co

(Volume 8 of Philosophy and Medicine series)

Dfl 60 US $\$ 31.50$ (paperback Dfl 30 US \$14.95)

The dominant emphasis in medical ethics during the last decade has been on specific moral problems of individual or small group decision-making. Analysis has concentrated on issues such as abortion, fetal research, care of the terminally ill, drug abuse and organ transplantation etc. The objective has been to articulate and assess the parameters for moral decision-making in these specific contexts of medical care. Insofar as bioethicists have stressed analysis of these 'micro' issues, there has been a corresponding lack of sustained analysis of the institutional character of medicine and health care provision - the 'macro' structure within which the micro issues arise. The Shelp volume attempts to correct the imbalance of focus by $I$ ) examining the health care institutions within which micro problems arise; 2) investigating the larger array of institutions of which the health care sector is only one part. Key concepts examined throughout the volume are those of 'justice', 'right', and their relevant application to the domain of 'health care'. But justice and rights considerations can only be clarified by examining various theories in terms of which certain claims about justice and rights are made and by means of which these claims can be defended. Without at least an implicit ethical theory or a theory of justice, certain questions cannot be coherently asked much less answered.

Such questions include: Is there a right to health care? What does such a right mean and imply with respect to an array of other basic rights we try to defend? What is the content of a right to health care? Are we claiming a right to free provision of medical care in crisis situations of disease and this for all members of society in an equal way or do we also include under the umbrella of this 'right' free access to the full range of technological provisions in medicine including such items as human in vitro fertilisation, heart transplants and cosmetic surgery (to name only a few of the procedures available which many would consider non-essential under a right to health care)? The parameters of rights claims are not self-evident and the essays in this volume show no presumption that their analyses offer final resolutions of these complex questions. They do, however, highlight some of the essential questions that would need to be asked in order to come to some plausible view as to the resolution.

Another question concerns the socio-economic and ethical issue of priorities. The priority question arises at two levels: the priority of health care relative to other goods and needs, and the order of priority of various forms of health care. While the issue of priorities is complex in terms of theoretical considerations it is no less so at the level of practical decision-making in any society faced with limited economic resources. Thus a third question, which asks about the justice or injustice of current health care systems, is a question which presupposes that we opt for a theory of justice that can argue for or against a universal right to health care and likewise provide a basis for defending priority decisions. It is not surprising, then, that the present volume on justice and health care will be considered as weak or as strong as are the theories of justice proposed to defend the various claims both at the micro and macro level of health care allocations.

DOLORES DOOLEY-CLARKE Department of Philosophy University College Cork, Ireland

\section{The Rights of Doctors and Nurses and Allied Health Professionals}

\author{
G J Annas, L H Glantz and B F Katz \\ New York, Avon Books \\ $\$ 3.95$
}

Doctors and nurses might be forgiven for believing that they have obligations and other people have rights so it was with some surprise that I received this book for review. My surprise was heightened when I saw that the cover described it as an 'American Civil Liberties Union Handbook'.

The book was suggested following one on the rights of hospital patients by one of the authors and from time to time the impression is given that the authors are more at home speaking of a doctor's 
duties than of his rights. The outstanding statement in the book for me came in the first page of the introduction 'almost all the time the interests of the health care provider and the patient are the same'. Doctors have always subscribed to this sentiment but how refreshing to see it acknowledged by those whose interests lie in health law rather than in patient care.

That the gulf between lawyer and doctor is by no means bridged is however made very apparent when one reads that 'understanding of the law can be as important to the proper care of patients as an understanding of emergency medical procedures or proper drug dosages'.

The scope of the book is indeed very much wider than its title might have one believe. Much basic information is given and a number of misconceptions corrected. As an example of the former the reader learns that the cost of malpractice insurance premiums rose from 250 million dollars in 1970 to 2 billion dollars in 1980 .

That the American doctor runs enormous risks in assisting at roadside accidents has for years been firmly believed by many in the UK. The authors firmly nail that one by telling us that there has been 'not one reported case in which a health care professional in this country has had to pay any money damages to anyone suing him for stopping and rendering aid and allegedly aggravating the patient's condition ...'

The book is written in the form of question and answer and this format permits the authors to cover a great deal of medical law in a manner readable to doctor and nurse. The profession's duty in respect of the disabled doctor is considered and the relationship between doctor and hospital administrator is explored.

Nursing and the law is investigated in some detail as are the respective liabilities of doctors, nurses and other health care professionals. The role of the social worker in the US is stated to be still ill-defined.

The chapters on consent, human experimentation and research and privacy and confidentiality emphasise to me the great similarities which exist between UK and US law. The chapter on the Union movement in health care in institutions is perhaps somewhat out of place in a book of this nature, but the one on malpractice litigation is a mine of information.

The appendices, which include a glossary of legal terms and an excellent index, conclude a book produced at a price which should ensure its purchase by all who have any interest in medical law in the United States.

J LEAHY TAYLOR Secretary Medical Protection Society London

\section{Light in Darkness: Disabled Lives?}

Papers on some contemporary medical problems, collected by the Medical Committee, Order of Christian Unity, London

Oxford, Unity Press, Mowbray and Co Ltd

$£ 2.25$

Here are 12 papers, mostly short and mostly new, though some are re-printed from elsewhere. There are three sections: (i) A Positive Approach to Life; (ii) Potential in Disability, and (iii) Dignity in Dying. The British authors are well known and $I$ assume that is true of those from the USA. The sections are preceded by an introduction on 'Some Dilemmas of Modern Medicine' by Sir John Peel. The general theme is the prevention and alleviation of disabilities, coping with disabilities and, in the end, coping with terminal illness. This theme was particularly appropriate in the International Year of the Disabled when the book was published. The attitudes of medical folk, the social services, parents and relatives are discussed, in addition to that of the sufferer. The aim of the book is to present a strong case against dealing with disabilities by any form of euthanasia or (with very few exceptions) by abortion. A Christian basis is advanced for this stance. Three of the contributors: Pat Seed, Gordon Scorer and Leonard Cheshire produce Christian meditations to support it. But how one moves from a basic stance to these particular ethical decisions is not discussed; nor why some Christians have arrived at different ones. The chapter on 'Why Abortion?' by a lecturer in logic, himself a paraplegic, does not resolve it. In his introduction Sir John says 'One of the difficulties that doctors have in the whole field of ethics is that morality is about absolutes . . . the value of human life is infinite. Doctors on the other hand are all the time having to make decisions based on the relative ...' Moral theory, however, is about both; and the phrase about human life by itself does not resolve the issues of medical ethics discussed in this book. A section of the report On Dying Well, produced by the Board of Social Responsibility of the Church of England in 1974 is reproduced and reads well after eight years. The publishers claim that the book is 'refreshingly new'. It is not. But its warnings and its positive points are important, if not as decisive as it thinks.

PROFESSOR RONALD PRESTON Faculty of Theology University of Manchester is

The Politics of Contraception: Birth Control in the Year 2001

\section{Carl Djerassi}

San Francisco/Oxford, W H Freems and Co

$£_{14.80}$ (paperback £6.95)

The Politics of Contraception was first published in 1979. This is a welcome re-issue with a new preface and an added article Birth Control in the Year $200 I$ although this does little more than summarise the contents of the original book.

Djerassi is a chemist who was closely $\overparen{\mathbb{C}}$ involved in the synthesis of the first oral $\frac{0}{7}$ contraceptive (the book includes an account of the chemical development of $\delta$ the Pill) but his interest in contraception is not only that of a scientist. He is concerned about world population growth and sees the control of fertility as the most urgent social issue of the next 20 years. $\mathrm{He}$ is also an industrialist $N$ who is very frank about the profit ${ }^{\circ}$ motive behind much scientific research $N$ in the United States. The result is a N fascinating book which considers the factors that affect the development, availability and use of contraceptive methods in the present and discusses $\stackrel{\mathbb{D}}{\oplus}$ how the interaction between science, $\stackrel{?}{+}$ industry and public policy may affect $\underline{T}$ future developments.

Dierassi touches on a number of ethi- $\mathbb{D}$ cal issues but his concern with conse- $\overrightarrow{\mathbb{D}}$ quences rather than with rights limits 